
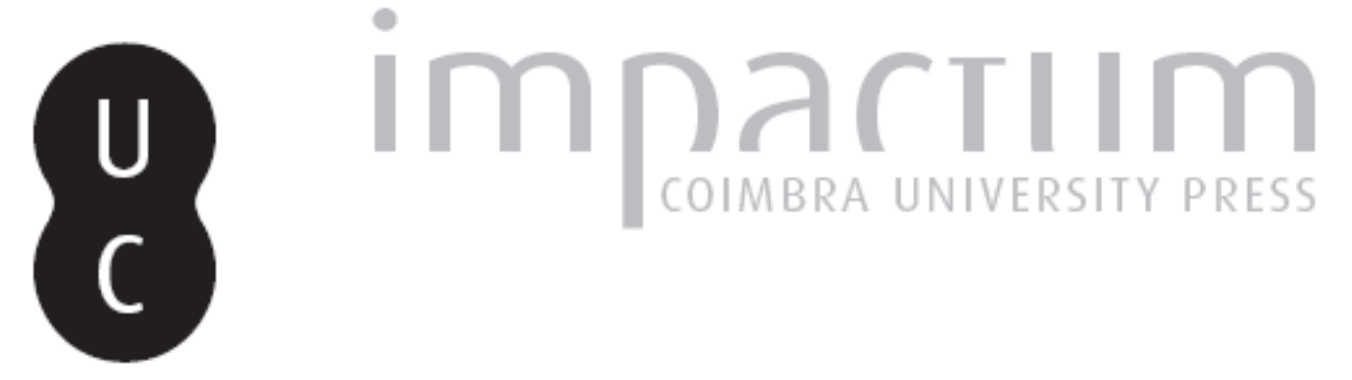

\title{
Análise dos incêndios florestais em Portugal e avaliação do ICRIF (Índice combinado de risco de incêndios florestais)
}

Autor(es): $\quad$ Bugalho, Lourdes; Pessanha, Luís

Publicado por: Associação Portuguesa de Riscos, Prevenção e Segurança

URL persistente:

URI:http://hdl.handle.net/10316.2/36163

DOI:

DOI:http://dx.doi.org/10.14195/1647-7723_16_15

Accessed : $\quad$ 26-Apr-2023 11:11:32

A navegação consulta e descarregamento dos títulos inseridos nas Bibliotecas Digitais UC Digitalis, UC Pombalina e UC Impactum, pressupõem a aceitação plena e sem reservas dos Termos e Condições de Uso destas Bibliotecas Digitais, disponíveis em https://digitalis.uc.pt/pt-pt/termos.

Conforme exposto nos referidos Termos e Condições de Uso, o descarregamento de títulos de acesso restrito requer uma licença válida de autorização devendo o utilizador aceder ao(s) documento(s) a partir de um endereço de IP da instituição detentora da supramencionada licença.

Ao utilizador é apenas permitido o descarregamento para uso pessoal, pelo que o emprego do(s) título(s) descarregado(s) para outro fim, designadamente comercial, carece de autorização do respetivo autor ou editor da obra.

Na medida em que todas as obras da UC Digitalis se encontram protegidas pelo Código do Direito de Autor e Direitos Conexos e demais legislação aplicável, toda a cópia, parcial ou total, deste documento, nos casos em que é legalmente admitida, deverá conter ou fazer-se acompanhar por este aviso.

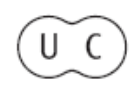




\section{territorium}

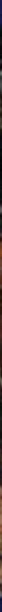

16

Revista da Associação Portuguesa de Riscos, Prevenção e Segurança 2009 


\title{
ANÁLISE DOS INCÊNDIOS FLORESTAIS EM PORTUGAL E AVALIAÇÃO DO ICRIF (ÍNDICE COMBINADO DE RISCO DE INCÊNDIOS FLORESTAIS) *
}

\author{
Lourdes Bugalho \\ Instituto de Meteorologia, Iisooa \\ laurdes.bugal hoameteo.pt \\ Luís Pessanha \\ Instituto de Meteorologia, Lisboa \\ luis.pessanhaameteo.pt
}

\section{RESUMO}

Os fogos florestais são um dos mais devastadbres desastres naturais que ocorrem em Portugal, especialmente durante o Verão. O Instituto de Neteorologia de Portugal (III) calcula um Índice de Risco de Incêndio Florestal, o ICRIF, que combina condiç̧̃es meteorológicas com o estado da vegetação e risco estnutural. O reprocessamento de 10 anos deste índice permitiu a sua análise e validação, comparando-o com áreas ardidas e viabilizando a sua utilização operacional.

Palavras-chave: Fogo florestal, risco de incêndio florestal.

\section{RESUMÉ}

Les incendies de forêt sont l'une des plus dévastatrices des catastrophes naturelles qui se produisent savent au Portugal, en partiarlier en été. L'Institut de Nétéorologie du Portugal (IN) cal arle un indice de risque feu de forêt, ICRIF, qui conbine les conditions de temps avec l'état de la végétation et des informations structurales. Ie processement de 10 ans de cet indice a permis son analyse et validation par raportaux surfaces brûlées, ce qui permet uneutilisation quérationelle.

Mbts-clé: Incendies de forêt, indice de risque d' incendies de forêt.

\section{ABSTRACT}

Forest fires are one of the most important natural disasters affecting Portugal, especially over the Sumer time with enormous direct economical impacts and also, by the indirect consequences of introducing fast changes on the land cover. The Portuguese Meteorological Institute (IIV) produces a Forest Fire Risk Index, the ICRIF, conbining meteorological conditions, vegetation status and stnuctural risk information. The reprocessing of 10 year of ICRIF is analysed together with the statistical classification of loumed forest areas, in order to assess the quality of ICRIF results.

Keywords: Forest fire, forest fire risk index.

\footnotetext{
* Commicação apresentada ao V Encontro Nacional e I Congresso Intemacional de Riscos.
} 


\section{Introdução}

Os fogas florestais são um dos mais devastadores desastres naturais que ocorrem frequentemente em Portugal continental durante o Verão, com impacto na economia, no ambiente e no clima. Para além das perdas directas resultantes do fogo, são introouzidas diversas alteraçães em especial:

i) no coberto vegetal, afectandb directamente o clima, pela variação da reflectividade da superfície e com consequências no balanço radiactivo

ii) na composiçãoda atmosfera (CO2, aercssóis, etc.) . Apenas uma gestão sustentável da floresta permite a sua adequada e contínua exploração.

O Instituto de Meteorologia (IIM) tem desde há muito desenvolvido esforças no sentido de formecer diariamente informação sobre o risco de incêndio florestal e, emparticular, o mapa de índice de risco ICRIF (Índice Combinado de Risco de Incêndios Florestais). Permite assim o acompanhamento temporal e espacial, em tempo quase real, da evolução do risco/probabilidade de incêndios florestais, nas diferentes regiões do país.

O ICRIF, que combina o índice canadiano FWI (Fire Weather Index) com o tipo e condições da vegetação, tem sido disponibi lizado desde 2004. Foi alterado em 2006 com a introdução de uma melhor resolução espacial e recorrendo à utilização do CORINE 2000 no levantamento do risco estrutural das florestas em Portugal Continental.

A validação dos índices de risco de incêndios florestais é sempre complicada. No entanto, é uma tarefa essencial já que permite demonstrar a uti i idade e a capacidade de resposta em particular em condições em que o risco se apresenta mais elevado. Toda a validação implica uma comparação com produtos independentes. No caso do risco de incêndio ICRIF, o que se pretende é validar a capacidade de resposta às condiçães de risco de incêndio florestal. Surge assim como natural a comparação com áreas ardidas ou com o número de ocorrências de incêndios florestais. No entanto, condições de risco baixo não implicam forçosamente que não existam incêndios florestais e, por attro ladb, condições de risco elevadb não garantem forçosamente incêndios. Para além de muitos autros factores, há a considerar o conbate aos fogos que podem contemplar a alteração das condições de uti i ização da floresta quando o risco é maior, o que pode atenuar ou mesmo evitar ocorrência e extensão de incêndios florestais. Assim, a validação do índice ICRIF pretende aferir a capacidade da sua util ização operacional, contribuindo com ganhas de eficiência na prevenção e combate de incêndios florestais, bem como aferir da introdução de correcçães caso se venham a verificar como essenciais.
A validação estatística do risco de incêndio ICRIF, depende muito da caracterização estatística dos incêndios florestais, o que toma necessário conhecer a forma camo se distribui ao longo do ano o número e a área dos incêndios florestais. Esta caracterização foi efectuada com base nos valores diários de áreas ardidas e de ocorrências, fomecidos pela Direcção Geral de Florestas para os anos 2001 a 2006.

Para a caracterização estatística foi efectuadb o reprocessamento do ICRTF com base nos valores do FWI existentes no IM em arquivo, para o período 1998 a 2007, durante as meses Maio a Outubro. Foi assim garantida a utilização do mesmo algori tmo durante todb o períodb. De referir que durante muitos anos o FWI foi calculado apenas para o período de Verão (15 de Maio a 15 de Setembro) , que aliás corresponde à maior parte das incêndios florestais em Portugal continental. Ná verdade, os incêndios florestais nestes meses, representammais de 90\% (fig. 1) das incêndios no total do ano, pelo que se pode considerar como uma boa estima dos valores anuais.

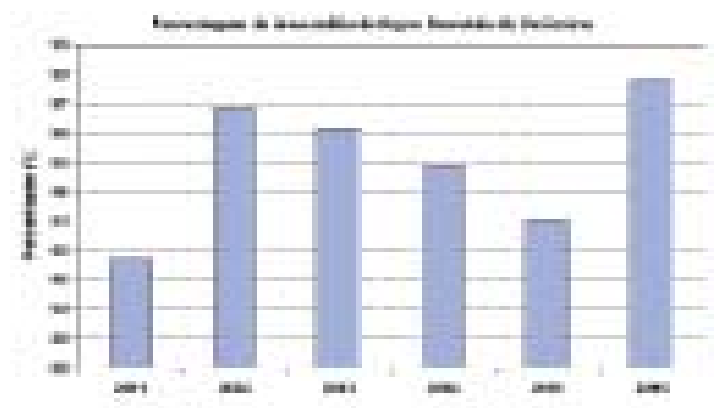

Fig. 1 - Percentagem de área ardida de incêndios florestais de verão/Ano.

\section{Incêndios Florestais em Portugal Continental}

No Verão estão criadas as condições para deflagração e propagação de incêndios. A origem de 10\% das incêndios florestais poole ser considerada como de causas naturais, 35\% de causas desconhecidas, 30\% devido a descuido e 25\% de origem criminosa [discurso do SEFAMAI no congresso Intemacional sobre Fogos Florestais (2003-01-31) ] .

A área ardida nos incêndios florestais está relativamente bem relacionada com a média da temperatura máxima de Verão (fig. 2) , com um coeficiente de correlação de 78\%. Como se pode doservar nesta figura, a área ardida nos anos de 1996 e 1999, apresenta valores inferiores aos que seria de esperar, considerando esta correlação. Da análise das razões para estas diferenças, constatou-se que, nestes anas, se dbservou ummês de Agasto não típico, com precipitação, especialmente em 1999, e com 


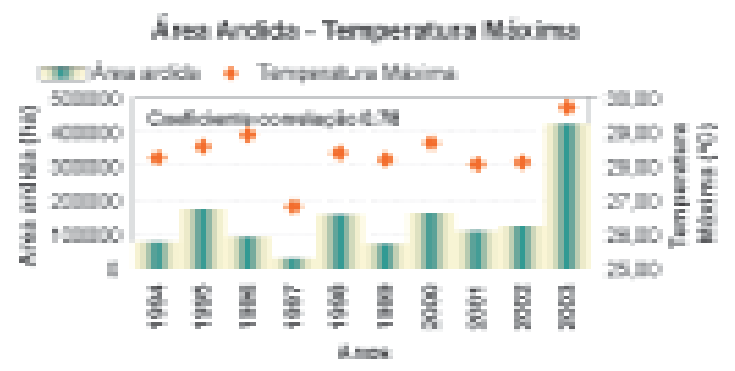

Fig. 2 - Relação área ardida e temperatura máxima média de Verão.

média da temperatura máxima inferior aos valores normais (1961-1990), seguido de um mês de Setenbro também com valores da média da temperatura máxima inferiores aos valores normais (dados do Departamento de Clima do Instituto de Meteorologia) .

É também interessante observar-se que o ano de 1997, que se apresenta como o ano mais quente até 2006 inclusive (Janeiro a Dezembro), foi caracterizado por um Verão com Junho e Julho de temperaturas inferiores às normais e em que Agosto esteve dentro das valores normais, pelo que a área ardida foi das mais baixas neste períodb.

Calculando a percentagem de área ardida no Verão em relação ao total do ano, no período de 2001 a 2006, verifica-seser, engeral, superiora 90\% (fig. 1).

considerandb o total anual de área ardida no país para o período de 1980 a 2006 (fig. 3) , doserva-se terem sidb os anos de 2003 e 2005, aqueles em que se observou maior área ardida, bem acima do valor médio adicionado de um desvio padrão.

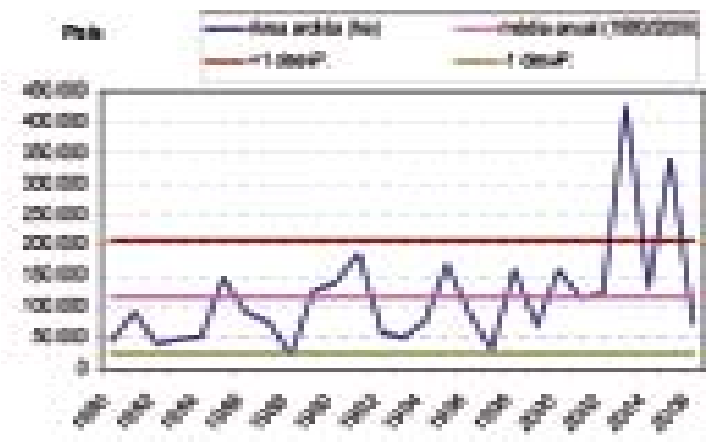

Fig. 3 - Área total anual ardida para o País, para o período $1980-2006$

No entanto, ao fazer-se a mesma análise por distrito, verificau-se que nalguns deles se doservou maior área ardida em 2003, enquanto noutros em 2005. Assim, nem sempre os distritos que apresentam valores de área ardida elevada num desses anos, a apresentam tambémno autro. Por exemplo, o distrito de Castelo Branco (fig. 4) apresenta umvalor elevado de área ardida para 2003, enquanto Viseu (fig. 5) apresenta um pico claro em 2005.

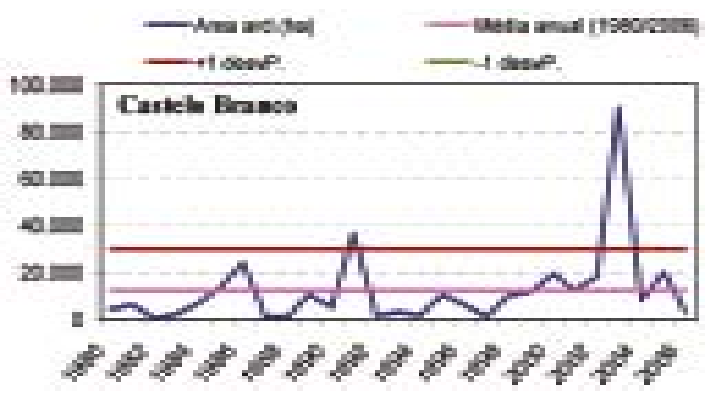

Fig. 4 - Área total amul ardida para o Distrito de Castelo Branco, para o período de 1980 a 2006.

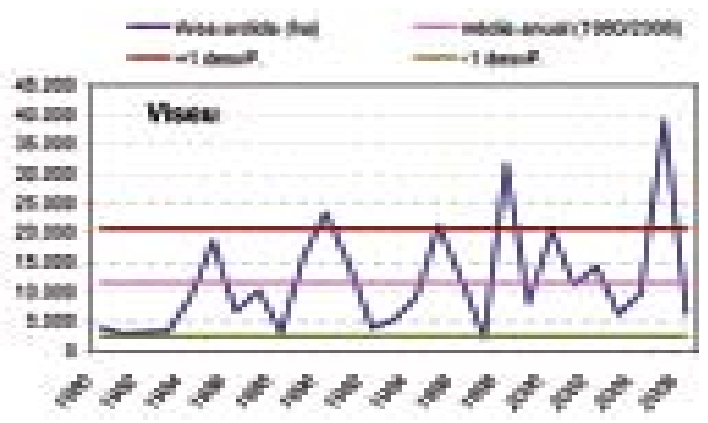

Fig. 5 - Área total anual ardida para o Distrito de Viseu, para o período de 1980 a 2006.

A razão para este facto deverá estar relacionada comvários factores locais no qual não se deve esquecer o tempo de recuperação da vegetação nos distritos com maior área ardida em 2003 bem como condições meteorológicas diferenciadas, como se exemplifica. para os distritos de Érora e Santarém (fig. 6e 7) .

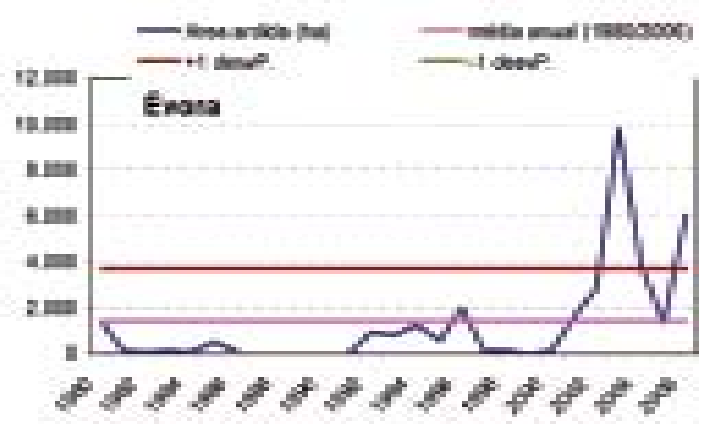

Fig. 6 - Área total amual ardida para o Distrito de Évora, para o período de 1980 a 2006.

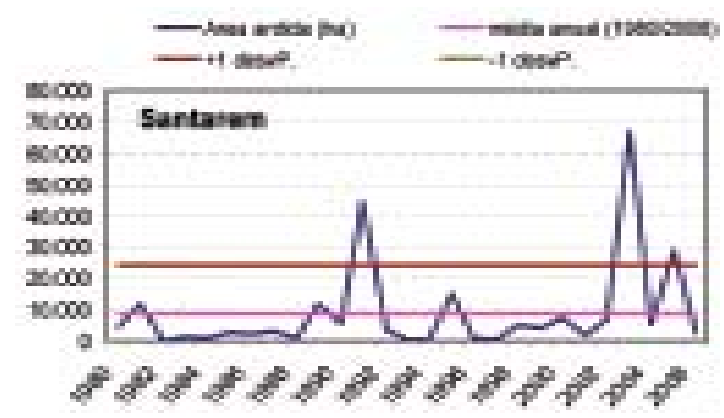

Fig. 7 - Área total amual ardida para o Distrito de Santarém, para o período de 1980 a 2006. 
Por outro lado, doserva-se que a variabilidade anul das áreas arcidas varia de distrito para distrito (figs. 4 e 5, 6 e 7). Assim, é importante que qualquer análise relacionada com os incêndios florestais seja feitaporcistrito.

\section{Índice Cambinado de Risco de Incêndios Florestais (ICRIF)}

$O$ índice ICRIF combina indicadbres:

- um Índice meteorológico FWI (Fire weather Index, Canadian Index)

- um mapa de risco estrutural, indicativo da facilidade de deflagração e propagação de incêndios florestais, frequentemente denominado mapa de combustível (fuel), baseado na base de dados de ocupação do solo CORINE 2000

- um índice de vegetação, o NDVI (Normalized Difference Vegetation Index), indicadbr db estadb de stress em que a vegetação se encontra.

Assim, o ICRIF representa um risco conjuntural, calculado através da combinação ponderada do risco meteorológico FWI, do risco estnutural associado ao combustível e do índice de vegetação NDVI.

Os pesos correspondentes a estes indicadores são valores seleccionados e compreendidos entre os 0 e os 100, para que o valor final do ICRIF esteja em geral compreendido também entre 0 e 100. Note-se, no entanto, que, sendo a escala do FWI uma escala aberta, a do ICRIF também o é. Existem assim vários valores pontuais de ICRIF superiores a 100.

\section{Indice meteorológico FWI (Fire weather Index)}

O FWI ("Fire Weather Index") é processado diariamente no Instituto de Meteorologia, a partir de parâmetros meteorológicos (temperatura e humidade relativa do ar, direcção e velocidade do vento a $10 \mathrm{~m}$ de altitude e quantidade de precipitação nas úl timas 24 horas) para 85 estações do Continente. Estes valores de FWI são posteriormente espacializados, calculando um valor para cada um dos pixels, para uma resolução de $1.1 \mathrm{~km} \times 1.1 \mathrm{~km}$, correspondente à resolução das imagens NOAA, no nadir do satélite, recebidas pela estação de recepção de satélites em utilização no IM.

\section{Indice estrutural, mapa de combustível}

O mapa de risco estrutural, é dotido com a mesma resolução (1.1 kmx $1.1 \mathrm{~km})$, a partir da base de dadas de ocupação do solo CORINE 2000 (COORdination of Information on the Enviroment) , que apresenta uma resolução inicial de 100m x 100m. Para cada um dos pixels, dbteve-se a área em cada uma das 44 classes de ocupação do solo. A cada uma destas classes, fez-se corresponder umvalor indicativo de facilidade de deflagração e de propagação de incêndios florestaisR.

Ovalor final de risco estnutural (fuel) em cada pixel é dado por:

$$
F\left(E L=\Sigma\left(A_{k} * R_{k}\right)\right.
$$

onde $A_{k}$ representa a percentagem de área coberta por cada uma das diferentes classes de ocupação do solo do CORTNE2000 e $R_{k}$ é o coeficiente de risco associado a essa classe.

Os fogos florestais conduzem a alterações da cobertura do solo, nas superfícies queimadas. A recuperação das espécies florestais ou da vegetação natural após os incêndios, depende de vários factores naturais (tipo de vegetação, água no solo, etc.) ou económicos e sociais (disponibilidade de verbas para a recuperação e reflorestação) , mas afectam sempre o mapa de risco estrutural de incêndios florestais.

A caracterização da cobertura do solo é anualmente feita localizando os pixels onde ocorreram fogos florestais nos três anos anteriores. Ovalor final no mapa de risco estnutural, actualizado no início da época dos fogos florestais (Abril) , é alterado por um factor de desagravamento no $1^{\circ}$ ano, de agravamento no $2^{\circ}$ ano, e, a partir do $3^{\circ}$ ano, de tendência para o restabelecimento db valor inicial. o mapa das ocorrências amuais de fogos é calculado recorrendo à variação do valor do índice de vegetação NDVI.

\section{Indice de Vegetação}

Un dos índices de vegetação mais utilizados é o NDVI, (Nomalised Difference Vegetation Index). Éde cálaulo simples, constitui umbom indicadbr db estadb e vigor da vegetação e está bem correlacionado com outros índices de vegetação de cálculo mais complicadb, tais como a fracção de cobertura do solo comvegetação (FVC) e o índice de área foliar (IAI) .

O NDVI é calculado recorrendo às medidas que neste caso são do radiómetro AVHRR/NOAA (Advanced Very High Resolution Radiometer) . A reflectância medida no canal 1 (Ch1, visível: 0.58 $0.68 \mathrm{~mm}$ ) e no canal 2 (ch2, infravermelho próximo: $0.725-1.0 \mathrm{~mm}$ ) são usados no cálculo:

$$
N D V I=(C h 2-C h 1) /(C h 2+C h 1)
$$

A diferença entre o infravermelho próximo e o visível apresenta valores positivos elevados no caso de vegetação verde, diminui fortemente para o caso de envelhecimento (ou stress) da vegetação, é próximo de zero para solo nu, e é negativo para superfícies de água, nuvens e neve, onde a reflectância no canal visível é superior ao do canal infravermelho. 
ONDVI é afectado por diferentes fenómenos toobs eles contribuindo para a redução do seu valor: a contaminação dos pixels por nuvens, pertunbaçães atmosféricas, variação do ângulo solar e da geametria de doservação do satélite.

Para o cálculo do índice ICRIF o valor do NDVI entra com um valor de compósito de 10 dias deslizantes: o valor de cada pixel corresponde ao máximo do valor de NDVI obtido ao longo dos 10 dias anteriores. Os dados do radiómetro AVHRR/ NOAA para o cálculo do NDVI são escolhidos seleccionando a melhor passagem do satélite sobre Portugal continental, isto é, a que apresenta menor valor do ângulo zenital de doservação do satélite nas passagem entre as 10UTC e as 13UTC, assegurando, ainda, que o ângulo zenital solar não seja superior a $55^{\circ}$.

\section{Resultados do ICRIF}

Desde 2006 que, de 15 de Maio a 15 de Outubro, época de fogos florestais, o índice ICRIF com a resolução de $1.1 \mathrm{~km} \times 1.1 \mathrm{~km}$, está a ser operacionalmente calculado.

Os resultados apresentam uma boa sincronização, quer com o aumento do risco, nos casos em que condições meteorológicas propícias a incêndios florestais se agravam, quer coma diminuição de risco, nos casos em que condições meteorológicas sofrem um desagravamento (L. ButalHo e L. Pessanha, 2007) .

Na análise das resultados feita combase em áreas de risco elevadb em cada distrito, calcula-se o número de pixels com valor de ICRIF que excede o patamar de risco 25 (considerado como o limite mínimo para situação gravosa) e 35 (situação muito gravasa) .

Para o cálculo do número de pixels por distrito com valores entre limites pré estabelecidos, foi necessário construir uma máscara que os seleccicnasse na mesma resolução da que é utilizada para nos mapas de ICRIF (fig. 8 e ThwA II) .

Cbtên-se, emgeral, boas correlaçães entre o número de pixels no distrito camvalores elevadbs do ICRIF ea correspondente área ardida ou número de ocorrências.

No entanto, esta correlação é, em geral, mais reduzida quando se relaciona com a área ardida do que a que é obtida com o número de ocorrências (figs. 9e10) .

Os valores de correlação mais baixos estão associados a meses e distritos com número de ocorrências significativo, mas, em geral, com reduzidas áreas ardidas (inferiores a 0.1 ha) , (L. Bugalio e L. Pessanha, 2007) .

Foi também diariamente calculado o número de pixels, em Portugal continental, convalores de ICRIF acima de 25 e 35 bem como o número de ocorrências

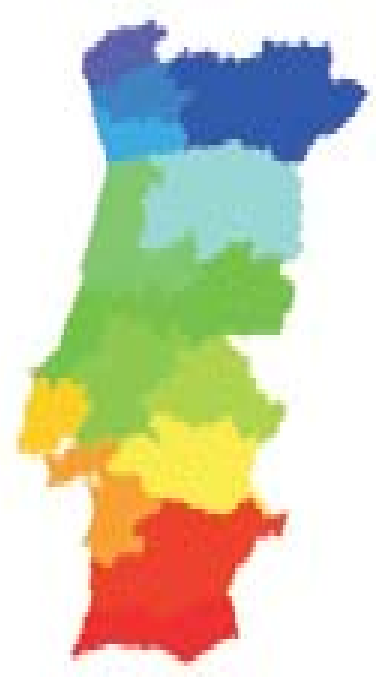

Fig. 8 - Mapeamento dos distritos de Portugal com a mesma resolução utilizada para o ICRIF.

TrFara II - Número de pixels em cada distrito

\begin{tabular}{|l|c|}
\hline \multicolumn{1}{|c|}{ Distrito } & Pixels \\
\hline Viana do Castelo & 3.299 \\
\hline Bragança & 9.700 \\
\hline Vila Real & 6.341 \\
\hline Braga & 3.980 \\
\hline Porto & 3.383 \\
\hline Guarda & 7.917 \\
\hline Viseu & 7.203 \\
\hline Aveiro & 4.025 \\
\hline Coimbra & 5.609 \\
\hline Castelo Branco & 9.295 \\
\hline Leiria & 4.889 \\
\hline Santarém & 9.249 \\
\hline Portalegre & 8.347 \\
\hline Évora & 9.982 \\
\hline Lisboa & 3.823 \\
\hline Setúbal & 6.763 \\
\hline Beja & 13.569 \\
\hline Faro & 6.508 \\
\hline
\end{tabular}

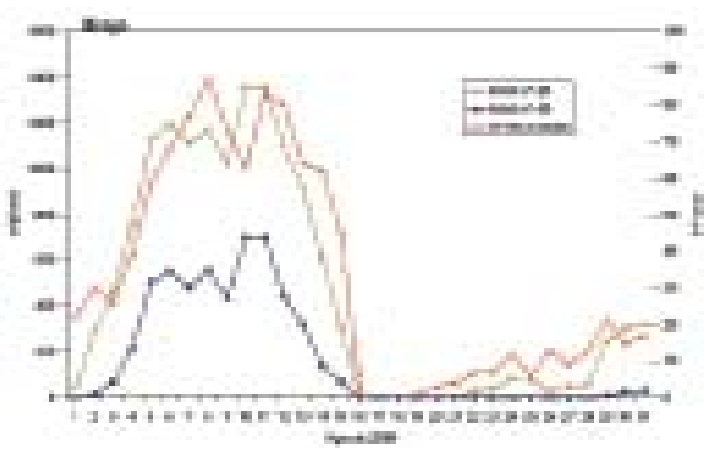

Fig. 9 - Número de pixels com valor de ICRIF >25 e >35 e o número de ocorrências de incêndios florestais para o distrito de Braga, em Agasto 2006. 


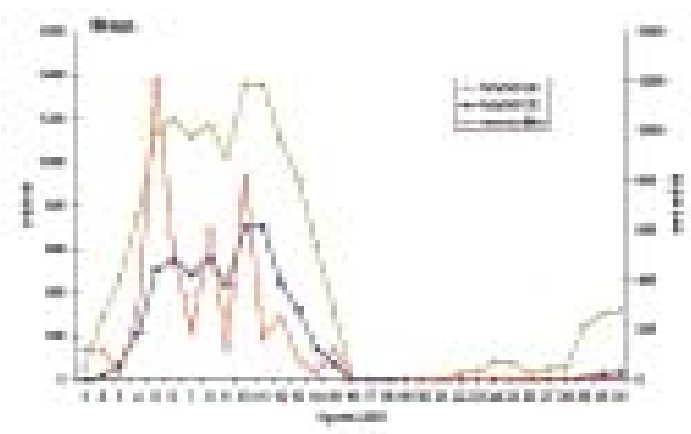

Fig. 10 - Número de pixels com valor de ICRIF $>25$ e >35 e o número de ocorrências de incêndios florestais para o distrito de Braga, em Agosto 2006.

e a área ardida. Os resultados para o ano de 2007, apresentam boas correlações com o número de ocorrências quer com a área ardida (fig. 11) .

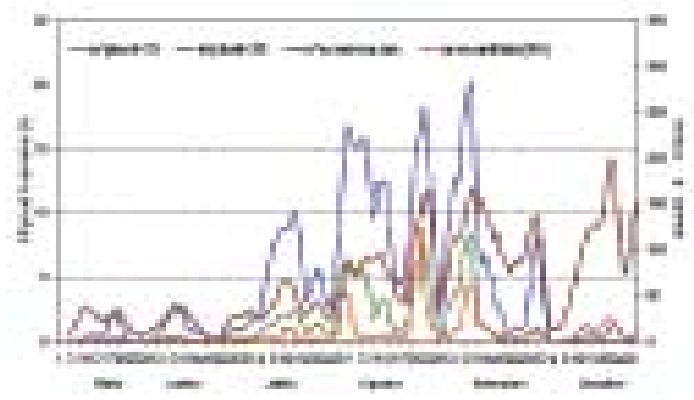

Fig. 11 - Número de pixels com valor de ICRIF $>25$ e >35 e número de ocorrências/área ardida para o País, durante a época de Maio a Outubro de 2007.

\section{Reprocessamento do ICRIF 1998 a 2007}

O ICRIF foi reprocessado para o período 19982007, para o qual existe calculado o FWI. Grande parte deste período refere-se apenas à chamada época de fogos florestais, de 15 de Maio a 15 de attubro. No entanto, o reprocessamento a partir de 2002 refere-se ao ano completo. Uma das motivações para este reprocessamento foi a necessidade de encontrar uma referência que permitisse anualmente comparar o comportamento do ICRIF ou seja, ter uma referência histórica (neste caso 10 anos) .

com base neste reprocessamento deu-se início ao estudb estatístico do ICRIF que foi realizadb em duas aproximações diferentes mas complementares:

- Aprimeira diz respeito à análise estatística dos próprios valores de ICRIF. Neste caso, foram calculados em cada pixel, as valores médios e máximos ao longo dos 10 anos.

- A segunda refere-se ao estudo de áreas com valores elevados (patamares) de ICRIF, istoé, ao número de pixels com valores de ICRIF acima de patamares pré-definidos (estes valores foram calculados em cada distrito) . São estas áreas de risco elevado que se pretendem relacionar com as correspondentes áreas ardidas.

Indice ICRIF porpixel

Com base no reprocessamento de 10 anos (1998-2007) e para a época das incêndios florestais, de 15 de Maio a 15 de Outubro, foram calculados os valores médios diários mensais (fig. 12) e respectivo desvio padrão, assim como o valor máximo mensal (fig. 13) .
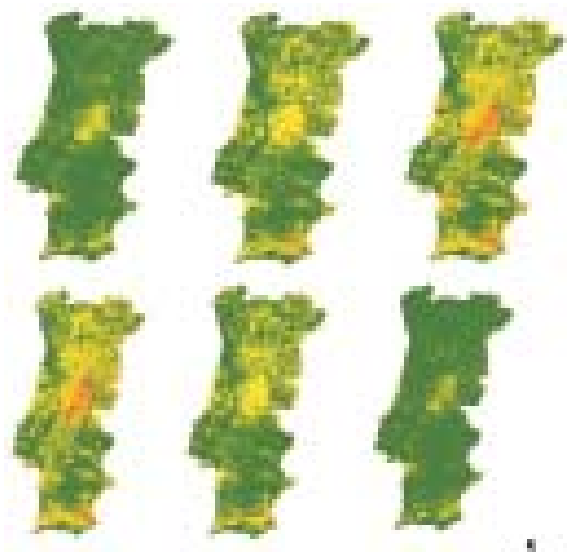

Fig. 12 - Média de ICRIF em Maio, Junho, Julho, Agosto, Setembro e Outubro (esquerda para a direita e do topo para a base) no período de 10 anos (1998-2007) .
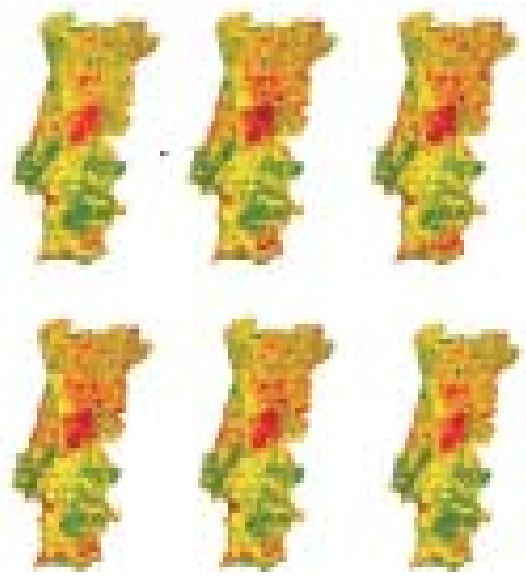

Fig. 13 - Valores máximos de ICRIF em cada pixel de Maio a Outubro (esquerda para a direita e do topo para a base) no período de 10 anos (1998-2007) .

Da análise da figura 12, podemos doservar que o valor médio do ICRIF é relativamente baixo em Maio, aumentandb em Junho e Julho, atinginab o valor méximo em Agosto, voltandb a diminuir en Setenbro e atubro. Isto significa que o risco de incênotios florestais é, en média, relativamente baixo em Maio, Setembro e attubro, sendb as meses de maiores riscos as de Junho, Julho e Agosto, como aliás era de esperar. 
Da análise da figura 13, podemos observar que todos os meses (Naio a autubro) apresentam valores elevados em vastas áreas do país. Se analisarmos estes resultados em conjunto com os da figura 12, podemos verificar que este facto é verdadeiro mesmo para meses com valores médios baixos, o que aponta para valores elevados do desvio padrão, especialmente nos meses de valores médios mais baixos (Maio, Junho, Setembro e Outubro). Isto significa também que, apesar de, em média, Maio, Setembro e autubro se apresentarem com baixo risco de incêndios florestais, anos existem em que os valores desse risco se apresentaram elevados.

\section{Indice ICRIF por olistrito}

Foram calculadbs as valores médios diários, e os respectivos desvios padrões do número de pixels com valores de ICRIF superiores a 25 e a 35, por distrito e para o período de 1998 a 2007 de Maio a Outubro. Castelo Branco é o distrito com maior percentagem média diária da área do distrito comvalores de ICRIF superiores a 25 (Agosto atinge 31\% do distrito) e 35 (Agosto 14\% da área do distrito) (fig. 14) .

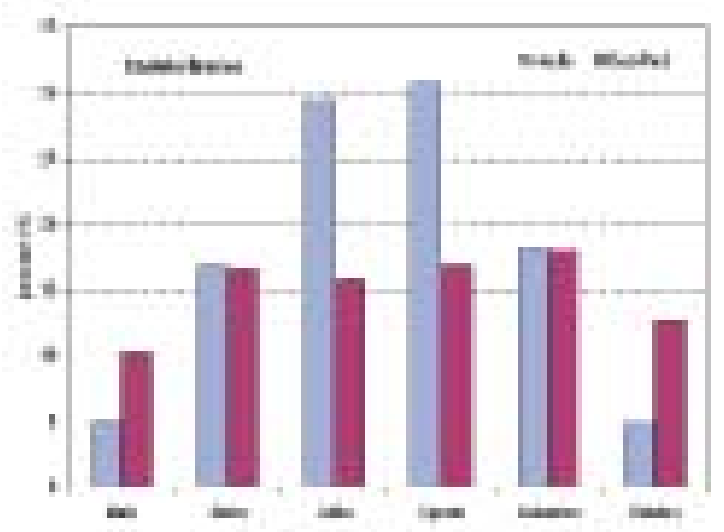

Fig.14 - Valor médio diário e desvio padrão do número de pixels com ICRIF superior a 25, em percentagem do número total de pixels, no distrito de Castelo Branco, calculado para o período 1998-2007.

Em geral, as valores médios diários do número de pixels com o valor do ICRIF acima de 25 são da ordem de 17\% em Agasto para o distrito da Guarda, de 15\% para os distritos de Coimbra, Faro, de 10\% para os distritos de Bragança, Leiria, Santarém, Visev e Vila Real, e inferior a 10\% para os restantes distritos da região do litoral norte e centro e do Alentejo (L. Burarho e L. Pessanta, 2009) .
Indice ICRIF versus área ardida

O estudo da relação do índice ICRIF com a área ardida, por distrito, foi realizado para o período 2001- 2006.

Foram calculadas as diferenças para os valores médios, anomalias mensais, para os diferentes anos quer do número de pixels com o valor de ICRIF superior a 25 e/ou a 35, quer das áreas ardidas. Mbstram-se dois exemplos para os distritos de Aveiro (fig. 15) e Castelo Branco (fig. 16), para alguns dos anos. Os restantes anos e distritos confirmam os resultadas aqui apresentadas.

Em geral, a área de risco elevado dada pelo número de pixels com valores de ICRIF acima de 25 ou 35, representa um bom indicador da área ardida. São dbservados alguns desfasamentos, como o caso de Aveiro onde, em 2003, a anomalia do ICRIF é grande em Julho e da área ardida em Agosto. Também se observa um desfasamento em 2003 para Castelo Branco, ande, apesar da anomalia positiva do ICRIF, esta não acompanha a das áreas ardidas.

Verifica-se que a evolução das duas anomalias estão em fase o que parece apontar para que o ICRIF constitua um bom indicador do risco de incênotios florestais.

Considerando agora as valores amuais do número de pixels com valor do ICRIF superior a 25 e as correspondentes áreas ardidas, os ajustes são bons para a grande maioria dos distritos e dos anos.

Estão representados nas figuras 17, 18 e 19, alguns dos distritos. De referir que para os distritos de Castelo Branco e Guarda, o ano de 2003 constituiu uma excepção pois as áreas ardidas estiveram claramente acima do esperado para a área de risco estimada pelo ICRIF (figs. 18 e 19) .

A explicação pode estar relacionada com várias razões, desde fogos intencionalmente ateados, a problemas de combate na dificuldade de acesso às regiões afectadas bem como também inerente ao próprio índice que pode não ter respondido correctamente à gravidade das situações.

Por outro lado, foram detectados neste estudo alguns problemas, ligados ao registo de dados dos incêndios florestais, emparticular no levantamento da área ardida, de impacto variável por distrito e por períodb de recolha e da responsabil idade da Direcção Geral de Florestas. Está provavelmente ligado à dificuldade de localização e registo de incêndios florestais, scbretudb em épocas de grande actividade. 
RISCOS - Associação Portuguesa de Riscos, Prevenção e Segurança
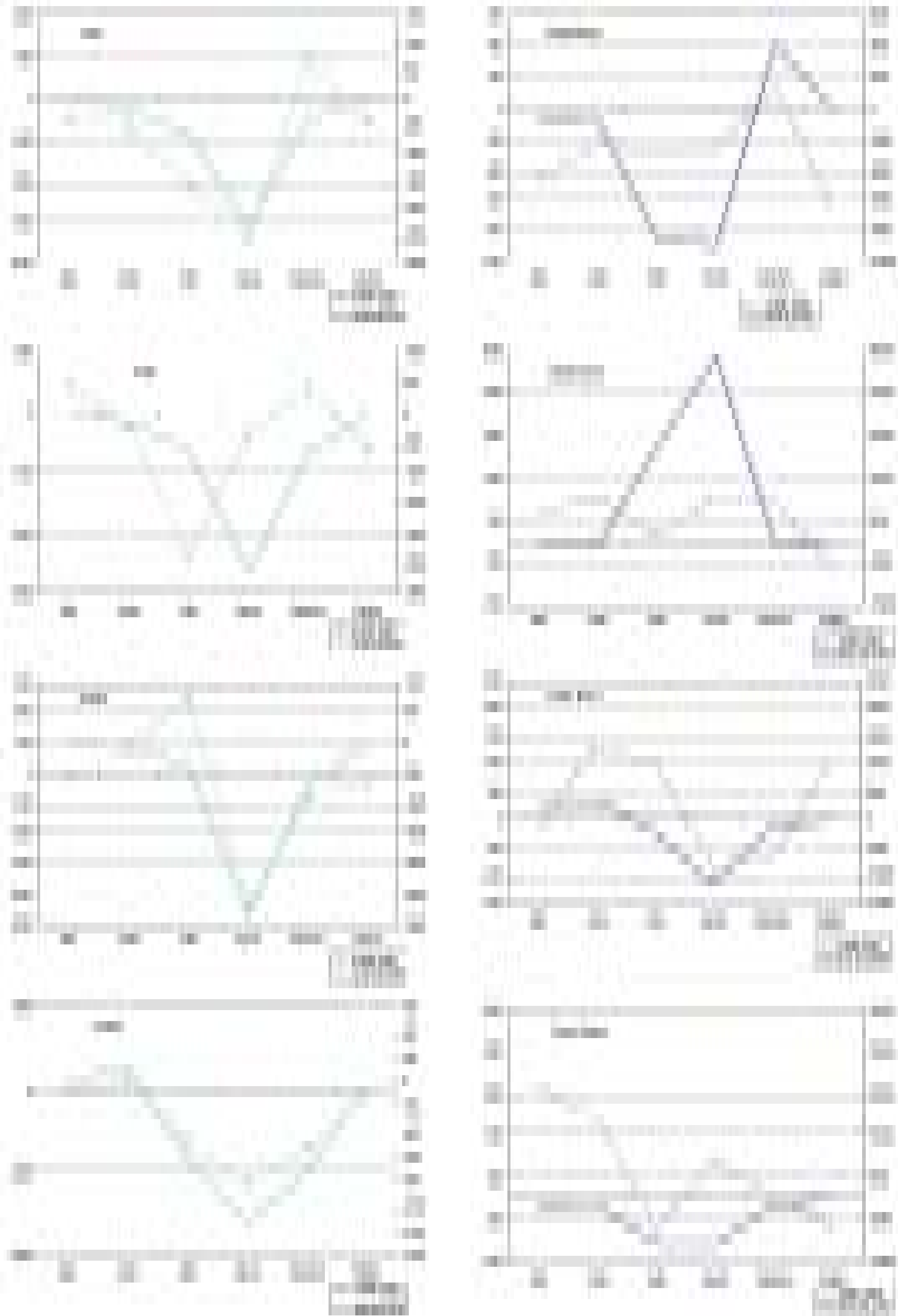

Fig. 15 - Anomalia do valor médio mensal do número de pixels com ICRIF superior a 25, e da área ardida, calculado para o distrito de Aveiro.

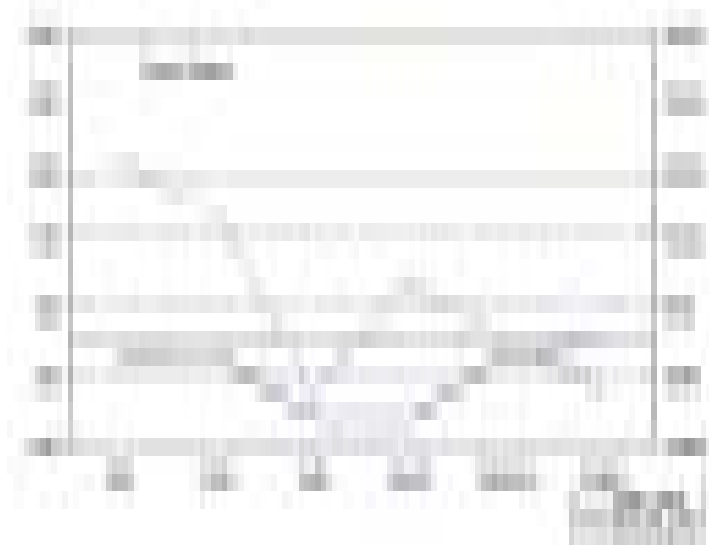

Fig. 16 - Anomalia do valor médio mensal do número de pixels com ICRIF superior a 35, e da área ardida, calculado para o distrito de Castelo Branco. 


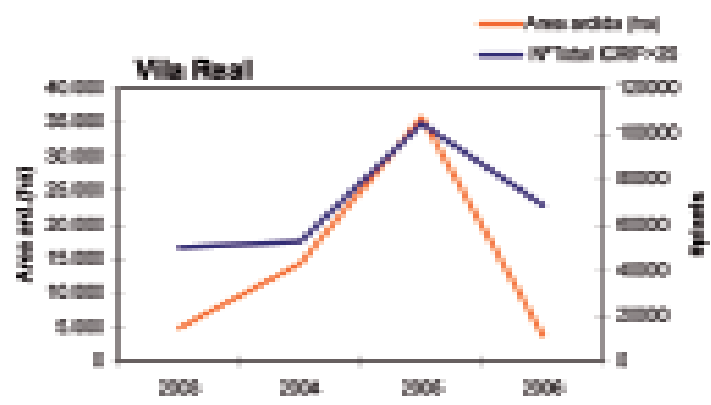

Fig. 17 - Evolução da área ardida total (ha) e do número de pixels com valor de ICRIF superior a 25 para o distrito de Vila Real.

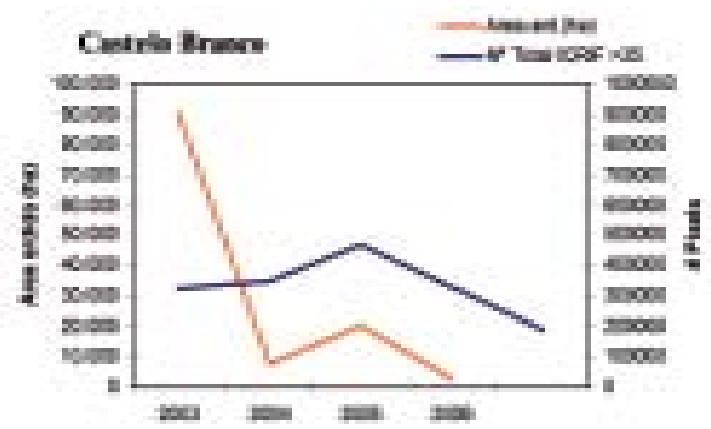

Fig. 18 - Área ardida total amual (ha) e número total anual de pixels com valor de ICRIF superior a 25 para o distrito de Castelo Branco.

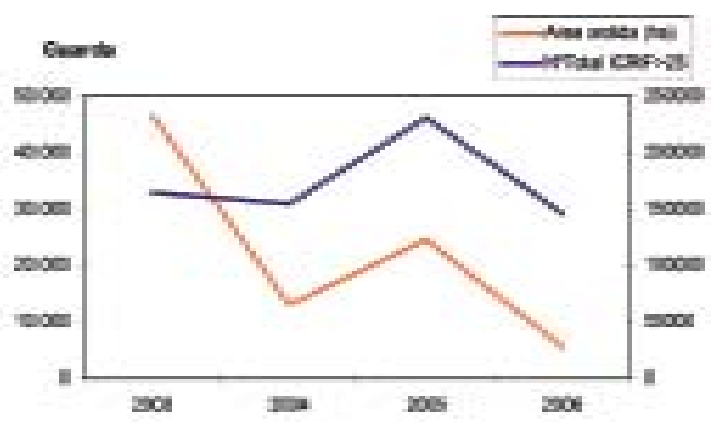

Fig. 19 - Área ardida total amual (ha) e número total amual de pixels com valor de ICRIF superior a 25 para o distrito da Guarda.

\section{Conclusões}

Da análise dos resultados pode concluir-se que o indice ICRIF mostra resul tados bem relacionados com áreas/ocorrências de incêndios florestais. Onúmero de pixels com ICRIF superior a 25 apresenta-se como umbom indicador do risco de incêndios florestais.

Mastra-se ainda que o valor médio do ICRIF varia significativamente entre Maio e Outubro, com o máximo, em geral, em Agosto, e que o correspandente desvio padrão é muitas vezes superior ao valor médio, especialmente nos meses de Maio e Junho e de Setenbro e autubro, épocas que apresentam em geral grande variabilidade.
O valor máximo do ICRIF tem uma variação ao lango das meses menor no período de análise (19982007) , indicando anos em que o valor máximo em Maio se aproxima dos valores de Agosto.

\section{Trabalho Futuro}

Ainda não se considera este trabalho como concluído. A validação do ICRIF deverá continuar pelo que se pretende no futuro:

- Melhorar as séries de incêndios florestais, corrigindo os dados de alguns problemas de registo;

- Continuar a estudar a série de áreas ardidas;

- Ajustar estatisticamente a série reprocessada db ICRIF por distrito;

- Relacionar os grandes incêndios florestais com o índice ICRIF.

\section{Referências Bibliográficas}

BOSSAPD, M. ; FERRNEC, J. ; OTAHE, J. (2000) - CORTNE Land Cover Technical Guide. Addendum 2000. Technical Report no 40, May 2000. European Envirorment Agency.

Burito, L. e PIRES, V. (2005) - "Monthly Analyse of NDVI at Portugal and their Relationship with Soil Water Balance". Proceeding of $4^{\text {a }}$ Simpósio de Meteorologia e Geofísica da APMG, 14 a 17 Fevereiro 2005.

BCAAH, L. e PtssanA, L. (2007) - "Análise e validação do Índice de Risco de Incêndio Florestal". Proceeding of $5^{\circ}$ Simpósio de Meteorologia e Geofísica da APMG, 5 a 8 Fevereiro 2007.

BURAIL, L. e PESSANA, L. (2009) - "IM ICRIF (Índice Combinado de Risco de Incêndios Florestais) : Estatística do índice para o perícob 1998-2007". Nota Técnica, DORE 01/2009 